\title{
COMMENT
}

\section{Potential for conflicting interests in those who participate in NVCD}

\author{
Andrew S. Bosworth* \\ Mahidol University International College, 999 Buddhamonthon, Salaya, Nakhon Pathom, 73120 Thailand
}

\section{ADDRESSING THE ARGUMENT FOR NVCD}

The ideas of ethical responsibilities held within Lemons \& Brown (2011, this issue) are for the most part sound and serve their purpose of eliciting thought; however, as was intended, there are points of contention and areas which deserve further consideration. From a philosophical perspective the argument in favour of non-violent civil disobedience (NVCD) towards the end of mitigating green house gases (GHGs) stands on 3 primary pillars: (1) justification based on the immorality of non-action, (2) action resulting in mitigation, and (3) action towards mitigation being preferable to directing resources to adaptation and other possible and just courses of action. With that in mind, Lemons \& Brown's (2011) paper aims to address several of those points but also to indeed open the discussion as wide as possible, away from pure ideals towards the pragmatic, which includes the financial complexities that convolute the moral argument for NVCD. The definition of 'morality', for the purpose of this paper will remain non-absolute.

\section{Establishing a moral claim}

The first pillar of the argument is built on the justification of the moral claim stemming from a consequentionalist appraisal of the difference of the cost-benefit analysis which incorporates values that may be more complex than the simple exchange values of economics. The core of the moral claim argument for NVCD is that the policy of the USA should be changed to take account of issues broader than economic values. However, this is the first and possibly most contentious issue: What are the units of this broader value? Are they similarly quantifiable or applicable? Is it appropriate to do so? Deciphering morality is the longstanding equation which eludes universally accepted answers. Such a factor as moral will insist that contentious debate will ensue and potentially derail any arguments for NVCD. The argument of harm inflicted by the developed countries, through a larger contribution to anthropogenic causes of global climate change (GCC), on developing countries insists that moral values which denote a limiting or mitigation of harm be considered. Simply put, the argument for NVCD is based on the moral rationale of being unable to bear the suffering caused by the actions of the developed countries, thus constituting a 'duty'. The rationale then poses the question of whether the motivation for NVCD is driven by either feeling guilty for inflicting harm or feeling compassion for the sufferers. The deeper question is: What difference does this distinction make when taking restorative action?

\section{Potential complications in the ethics of NVCD}

Lemons \& Brown's (2011) paper makes a clear note of the model of a 9 billion plus world population by 2050 , and the need for a $50 \%$ reduction of greenhouse gases (GHGs) from food production in addition to drastic reduction of deforestation and methane output in agriculture. There have been calls to recognize the likelihood of a food crisis in the short and long term as a result of GCC (Crib 2010). Forcing producers of the food industry to undertake such drastic cuts through new methods or cuts in production would surely result in a considerable rise in food prices due to the need for new technology for both energy efficiency and adapted practices in agriculture (IPCC 2007). Consequently, these measures would decrease food availability and add further hardship to the 'at risk' groups. The question remains whether the goal of GHG reduction in the immediate future increases the risk of negative consequences that may add to a food crisis and whether such potential weighs against the moral argument for or against NVCD.

Lemons \& Brown (2011) made a clear point against delving into the issue of a possible backlash against 
protestors who choose to follow methods of NVCD, while the personal dangers were not dealt with beyond suggesting that the legal consequences may not follow previous models found in the parallel examples of slavery, segregation, discrimination against women and protest against atmospheric nuclear testing. However, the larger issue of the socio-economic consequences of taking a hardline in reducing GHGs should be considered as a moral issue. Nearly 6 trillion Euros of assets, have been put into reducing GHG emissions by a single European group, the Institutional Investors Group on Climate Change (IIGCC), which includes pension fund managers amongst its ca. 70 members. 'The IIGCC brings investors together to use their significant collective influence to engage in dialogues with policymakers, investors and companies to accelerate the shift to a low carbon economy' (see www.iigcc.org/). The American counterpart, the Investor Network on Climate Risk (INCR), represents 90 American institutions and 9 trillion USD (members can be found at www.incr.com/).

These are examples of a type of investing that depends on the reduction of GHG emissions and the shift to a lowcarbon society to maintain profits. If a drastic cut is made in GHG emissions that may result in uncalculated potentials, the economic fallout could ostensibly have a negative impact on a wide segment of society in developed nations. Such consequences may weigh against the moral argument for NVCD, or at least add to the counterargument, and possibly create a situation where the ethical objectivity or integrity of those who make claims towards taking a hardline stance, such as NVCD, towards mitigation of GHGs is questioned, especially if their pensions are affected and profits incurred as a result of mitigated GHGs. One example of this would be any members to the Universities Superannuation Scheme (USS) which caters for those in European higher education specifically. It is stated clearly that the 'USS has a responsibility to ensure that any employers accepted into the scheme do not have a negative impact on the funding of the scheme' (see www.uss.co.uk/HowUssIsRun/ employers/Pages/default.aspx/). Thus a case for a breach of integrity could be extrapolated. That NVCD intended to force policy to mitigate GHGs falls into the category of desirable action from the point of view of the INCR and IIGCC may appear suspect or suggest a lack of integrity (INCR 2010; press release and suggested domestic action towards the ideal of meeting the goals of the Annex in the Copenhagen Accords). The complexity of the economics and potential for unforeseen hardships based on investment and perception of low-carbon economies force the issue of NVCD away from moral duties or ecological justice towards much more convoluted ideals, potentially placing private investment, governments and other stakeholders in ecological equilibrium disturbed by GCC at odds.
The second pillar is based on the assumption that mitigation is achievable, and that by taking a moral stance through NVCD positive pressure can be put on policymakers to achieve that goal. The arguments by Lemons \& Brown (2011) outlined above make distinct points against the feasibility of GCC mitigation aiming at $\mathrm{a}<2{ }^{\circ} \mathrm{C}$ rise in average global air temperature; however, taking GCC mitigation as the sole end upon which NVCD is focused concedes a potential for failure which must be taken account of. That the actions required to cut GHG emissions to the levels required to mitigate GCC are so drastic, as mentioned before, may result in hardships and suffering that mitigate the moral claim justifying NVCD.

The third pillar of the argument is a logical extension based in-between justice and morality: if a duty to mitigate GHGs emissions in the hopes of mitigating the effects of GCC is the means, then the end is to mitigate the suffering, and any path leading to that end should serve equally as well. Simply put, stopping the cause is not the same as fixing the damage, from which the moral claim falls into theories of justice. In this case, perhaps a more practical goal, as it allows for more pragmatic solutions, is NVCD in the name of 'aiding those who suffer as a result of GCC', in whatever form the victims and perpetrators agree upon, in a form of restorative justice. The imagery of slavery was invoked to impress the severity of the moral claim. If they are to be freed, what is the most effective method to do so? Such a goal could possibly remain free from the potentially negative and unintended consequences of GHGs mitigation, such as rising food prices and the potential economic benefits for those who are proponents of mitigation.

\section{CONCLUSIONS}

If the 3 pillars of Lemons \& Brown's (2011) argument for NVCD remain, we must reiterate the corresponding questions: (1) Is it immoral not to act in favour of immediate mitigation of GHGs? (2) Is it pragmatic to mitigate the anthropogenic effects of GCC? (3) Would adaptation be a more appropriate response to GCC than mitigation? This Comment suggests that while NVCD may serve as an indicator of the positive moral move away from apathy, the delicate balance of moral and ethical consideration associated with GHGs and GCC might be damaged by an overly enthusiastic move towards a single end, as it may shadow the other moral lessons that may be learned through a positive understanding of the complex intertwining of economic, scientific and geopolitical aspects. Further questions to be addressed in the same area of discourse are as follows: (4) Does 
NVCD focusing on mitigation take resources that could be better used to another end? (5) Does NVCD focusing on mitigation of GHGs confuse a complex moral issue to the detriment of the moral claim? (6) Are there conflicts of interest in purposing or participating in such action? If taken separately, the case for NVCD based on a moral claim appears strong. However, unless the economics of transition to a low-carbon society become more transparent there exists a potential for those protesting using NVCD to also benefit financially from doing so, thus suggesting a conflict of interest weighing against the moral claim.

Editorial responsibility: Darryl Macer, Bangkok, Thailand

\section{LITERATURE CITED}

Crib J (2010) The coming famine. University of California Press, Berkeley, CA

IPCC (Intergovernmental Panel on Climate Change) (2007). Climate change 2007: synthesis report. Summary for policymakers. IPCC, Geneva. Available at www.ipcc.ch/ pdf/assessment-report/ar4/syr/ar4_syr_spm.pdf

Lemons J, Brown DA (2011) Global climate change and nonviolent civil disobedience. Ethics Sci Environ Polit 11:3-12

INCR (Investor Network on Climate Risk) (2010) Global investor statement on climate change: reducing risks, seizing opportunities and closing the climate investment gap. INCR, Boston, MA. Available at www.incr.com/ Document.Doc?id=648

Submitted: November 18, 2010; Accepted: February 15, 2011 Proofs received from author(s): April 10, 2011 